\title{
ORIENTAÇÃO ACADÊMICA E A PANDEMIA DA COVID-19
}

DOI: 10.37702/2175-957X.COBENGE.2021.3505

Tais Maria Souza Ribeiro - tais.ribeiro@aluno.ufop.edu.br

Universidade Federal de Ouro Preto

Rua Alfa 172

35400-000 - Ouro Preto - MG

Bruna Fernandes de Souza - bruna.fernandes1@aluno.ufop.edu.br Universidade Federal de Ouro Preto

Praça Manoel José do Nascimento 100

35661-332 - Pará de Minas - MG

André Martins Ferreira - andremferg@gmail.com

Universidade Federal de Ouro Preto

Rua Cotochós 481

33600-000 - Pedro Leopoldo - MG

Vinicius Guimarães Soares - vguimaraes602@gmail.com

Universidade Federal de Ouro Preto

Rua Rosa Maria Guimarães 05

35430-313 - Ponte Nova - MG

Carlos Alberto Pereira - pereiraufop@gmail.com

Universidade Federal de Ouro Preto

Rua João XXIII 240

35400-000 - Ouro Preto - MG

Resumo: O presente artigo apresenta as adaptações feitas pela Orientação Acadêmica do curso de Engenharia de Minas da Universidade Federal de Ouro Preto - Minas Gerais (OAEM UFOP-MG), ao longo do ano de 2020, para a garantia do desenvolvimento do projeto em tempos de pandemia da Covid--19. Tendo a missão de possibilitar a inserção dos alunos no ambiente acadêmico da cidade de Ouro Preto e, principalmente, reduzir o índice de evasão, o projeto ocorreu de forma remota explorando as diversas possibilidades oferecidas pela internet. Conteúdos em vídeo, palestras online sobre o curso e assuntos correlatos à área da Engenharia de Minas, quizzes e dinâmicas de grupo estiveram entre as 
atividades desenvolvidas com 30 novos alunos do curso. Alguns dos resultados alcançados foram o feedback positivo dos orientandos e a constatação de departamentos dentro da UFOP e de outras instituições da relevância de um grupo de apoio voltado para novos discentes. A despeito da inviabilidade dos encontros presenciais, atendendo às medidas de isolamento social recomendadas pela Organização Mundial da Saúde (OMS), o projeto expandiu sua atuação e contribuiu para a permanência dos alunos no curso. Dados divulgados pela UFOP indicam que a taxa de evasão do curso registrou queda em 2020 na comparação com 2019, ano de atividade presenciais regulares. Com isso, verifica-se a relevância do projeto para o fortalecimento da maior missão de uma universidade: formar profissionais e cidadãos.

Palavras-chave: Orientação Acadêmica. Engenharia de Minas. Adaptação. Covid-19. Projeto de ensino. 


\section{ORIENTAÇÃO ACADÊMICA E A PANDEMIA DA COVID-19}

\section{INTRODUÇÃO}

O ingresso no ensino superior representa um marco importante na vida de qualquer pessoa. São vários os motivos que levam alguém a considerar a graduação um caminho para concretizar objetivos de vida (Côrrea e Lacerda, 2011). Construir um futuro diferente, obter qualificação profissional, mudar o destino da própria vida e até mesmo ingressar em outra área de formação, visando novas oportunidades.

Não obstante, nem sempre tais objetivos são alcançados, por diversos motivos, ou mesmo vários desafios que surgem como obstáculos à sua concretização (Sales et al., 2016). Também são vários os motivos que levam os alunos à evasão universitária. Segundo dados da Pesquisa Nacional por Amostra de Domicílios (PNAD) de 2019, cerca de 1 a cada 5 alunos abandonaram o ensino superior (Hermes, 2021) ao longo do ano de 2018. $O$ principal deles, pontua-se, é a desistência do curso de graduação nos períodos iniciais, em decorrência da grande dificuldade de adaptação ao novo cotidiano (Garbin, 2012).

O sistema universitário faz com que o jovem ingressante de um curso superior comece a desenvolver responsabilidade e autonomia por sua aprendizagem. Saber administrar o seu tempo, definir metas, estratégias de estudos, construir relacionamentos interpessoais e se adaptar a um novo ambiente são algumas das dificuldades enfrentadas pelos alunos ingressantes em um curso (Soares, Almeida, Diniz \& Guisande, 2006). Segundo Robbins et al., (2004), o ambiente acadêmico e sua vivência são baseados na integração social e na integração acadêmica. A ambientação dos alunos à universidade e aos outros estudantes refletem diretamente na decisão de permanecer ou abandonar 0 curso e permite que todas as pessoas desfrutem de oportunidades, de forma a atingirem maiores aproveitamento e desempenho acadêmico e pessoal, gerando um sentimento de pertencimento ao espaço universitário.

No intuito de fomentar a colaboração entre os próprios alunos, principalmente para fornecer apoio e incentivo àqueles ingressantes, o Departamento de Engenharia de Minas da Universidade Federal de Ouro Preto (DEMIN - UFOP) percebeu a necessidade de criar uma entidade interna, surgindo assim a Orientação Acadêmica da Engenharia de Minas (OAEM), em 2013. Composta por alunos matriculados em períodos diversos do curso e um professor orientador, o grupo tem como missão principal a redução da taxa de evasão do curso, auxiliando os alunos calouros a vencerem as dificuldades iniciais impostas pela nova rotina do curso superior, ajudando-os no entendimento dos conteúdos das disciplinas, como também fomentando uma maior a frequência e melhor aproveitamento (Fonseca et al., 2019).

A pandemia da Covid-19 trouxe para alunos e professores a necessidade de urgência e adaptações nos métodos de ensino, frente ao isolamento social e a continuidade dos estudos (Santos e Zaboroski, 2020). Apesar do aumento na expectativa de responsabilidade individual por parte do aluno em sua formação e adesão ao curso, verificase que certas características do ambiente universitário, tais como a oportunidade de interação com professores e de envolvimento em atividades extra-classe, favorecem a integração do aluno ao contexto universitário (Capovilla \& Santos, 2001; Fior \& Mercuri, 2003; Kuh, 1995; Kuh \& Hu, 2001).

Nessa conjuntura, a OAEM se viu impelida a alterar as formas de estabelecer contato com os alunos orientandos e de desenvolver as atividades, vez que os encontros presenciais passavam a estar descartados devido à pandemia. Assim, o objetivo principal do presente artigo foi apresentar as medidas e adaptações das atividades, o que 
possibilitou ao grupo levar informações relevantes aos alunos atendidos pelo projeto, contribuindo para a ampliação do aproveitamento e do interesse dos mesmos em prosseguir os estudos. Ademais, a atuação do projeto de forma remota, assim como presencialmente, faz parte das diretrizes curriculares das Atividades Acadêmicas Científicas e Culturais (AACCs), concedendo 30 horas para os alunos que tiverem $75 \%$ de participação nas atividades e 45 horas por semestre para os orientadores.

\section{METODOLOGIA}

A equipe de orientadores do projeto é formada por seis alunos de períodos variados e selecionados através de um processo onde é levado em conta a experiencia nas disciplinas do primeiro período. No início de março de 2020 , os orientadores do projeto fizeram uma visita à aula de Geometria Descritiva, está previamente acordada com o professor da disciplina, a fim de apresentar o projeto aos alunos ingressantes do curso de Engenharia de Minas. Nessa oportunidade, ressaltaram-se as principais diretrizes da Orientação Acadêmica voltadas à integração dos alunos à vida acadêmica. Foi feita, ainda, a apresentação das entidades e das possibilidades no contexto universitário, como participação em projetos, iniciações cientificas, dentre outras atividades. Nesse primeiro contato, foram coletados os números telefônicos dos alunos com o objetivo de ser criado um grupo na rede social "WhatsApp" para a facilitação da comunicação entre orientadores e orientandos. Ao fim dessa visita, acontece um "tour" pelo campus da universidade. Dessa forma, os novos alunos tiveram a oportunidade de se situarem na instituição, conhecendo os principais prédios e departamentos da universidade. Por fim, foi feito o convite aos alunos para participação no projeto, que acontece por meio de encontros semanais presenciais no Departamento de Engenharia de Minas (DEMIM) com o desenvolvimento de atividades previstas em no planejamento semestral.

Uma das principais finalidades do projeto foi e é evitar a evasão dos discentes do curso no primeiro período da trajetória acadêmica dos mesmos. Sendo assim, a taxa de evasão do curso torna-se um parâmetro fundamental de avaliação da efetividade do projeto. Ao final de todos os períodos, a universidade disponibiliza uma planilha, por meio da plataforma do "Minha UFOP", contendo os dados e motivos referentes ao cancelamento de matrícula ou desligamento dos cursos.

Com a pandemia da Covid-19, as aulas foram suspensas no final de março, bem como os encontros da Orientação Acadêmica. Esta situação levou ao surgimento de incertezas diversas e grande apreensão entre os alunos. O grupo na plataforma do "WhatsApp" foi imprescindível e de notória relevância nesse período, uma vez que agregou em variados aspectos, como a facilitação da interação entre orientadores e orientandos. A partir desse contato, foi possível identificar o aumento da ansiedade entre os alunos orientados do semestre 2020.1. Diante disso, surgiu a necessidade de adaptar o projeto para melhor atender e apoiar os alunos em um período tão atípico. Foram traçadas novas estratégias para que o projeto cumprisse sua função, ainda que de forma remota. Os orientadores realizaram o acompanhamento semanal pelo grupo do "WhatsApp", desenvolveram encontros síncronos e disponibilizaram conteúdos diversos aos alunos.

Para direcionar as atividades, foram elaborados questionários no "Google Forms" a fim de extrair informações a respeito da saúde mental dos alunos, os métodos de estudo por eles empregados e os interesses em relação ao conteúdo a ser disponibilizado. Inicialmente, o grupo no "WhatsApp" serviu para o envio de informações sobre a universidade e o reflexo da pandemia no retorno das atividades acadêmicas. Para maximizar o alcance do projeto, as atividades foram divulgadas, também, em outras redes sociais, dentre elas o "Instagram", o "Facebook" e o "Youtube". Embora o projeto já 
contasse com um perfil nessas redes sociais, o uso das mesmas se tornou mais frequente devido ao formato em que o projeto teve de se enquadrar.

A partir das informações coletadas junto aos alunos, os orientadores optaram por, inicialmente, produzir e divulgar vídeos curtos com profissionais da mineração e professores com o objetivo de despertar e manter vivo o interesse dos alunos pela universidade e pelo curso. O primeiro da série de vídeo tratou de saúde mental no período de pandemia. Neste, uma profissional da psicologia falou sobre ansiedade e deu dicas de estratégias de produtividade nos estudos. Posteriormente, foram postados vídeos sobre as atribuições e perspectivas do engenheiro de minas, assunto tratado pelo professor do DEMIN, José Aurélio; Lavra subterrânea, conteúdo de estudos e pesquisas, pelo também professor do Departamento José Margarida da Silva; experiências profissionais e acadêmicas, abordado pela engenheira de minas Ângela Avelar; colegiado e normas do curso, novamente pelo professor José Margarida da Silva; engenharia ambiental, assunto abordado pelo professor José Fernando Miranda; experiência profissional em gerenciamento de setores e gestão ambiental, pelo contador Maurílio Pontes; gerenciamento de projetos para indústrias de mineração, petróleo e gás, metal e processos, assunto abordado pelo engenheiro elétrico Kezer Almeida. Concomitantemente à divulgação destes conteúdos, os orientadores repassaram aos calouros sugestões de filmes, documentários, sites e cursos profissionalizantes gratuitos voltados para a área da Engenharia de Minas.

Por meio da plataforma "Canva", foram criadas artes informativas e, ao mesmo tempo, sucintas. Para levar informação de forma dinâmica, os orientadores desenvolveram o "Você Sabia?" e o "Top 7", seções que consistiam em curiosidades relacionadas ao curso de Engenharia de Minas e às áreas de atuação de seus profissionais. Uma vez identificado o interesse dos alunos por esse tipo de conteúdo, por meio de balanços de acesso disponibilizados pelas redes sociais, a utilização de tais ferramentas foi intensificada. No Instagram, por exemplo, os orientadores fizeram uso dos "stories", para postar "quizzes" sobre assuntos e disciplinas específicas do curso. Tais desafios interativos tiveram como temas: mineralogia, geologia geral, utilização de minérios, vida universitária ouro-pretana e entidades acadêmicas. Por meio, também, dos "stories" foram divulgados registros fotográficos de Ouro Preto feitos pelos próprios "calouros", bem como pelos orientadores do projeto, para manterem-se vivas, assim, as lembranças da cidade e as expectativas pelo retorno às atividades presenciais, além de destacar importância dos aspectos culturais e sociais da cidade de Ouro Preto.

De agosto a outubro de 2020, a Universidade Federal de Ouro Preto (UFOP) ofertou aos alunos matriculados um Período Letivo Especial (PLE). Seria facultada a possibilidade de cursar até duas disciplinas. Mais uma vez, o projeto marcou sua importância, visto que os alunos precisariam de informações e dicas. Os orientadores buscaram detalhes a respeito do PLE, de forma a trazer respostas e soluções diante dos questionamentos, bem como ajudar os alunos ingressantes na escolha das disciplinas e na manifestação de interesse em cursá-las. Os alunos receberam, ainda, dicas de como obter maior rendimento nos estudos, que, obrigatoriamente, se dariam de forma remota. Por meio da plataforma "Google Meet" ocorreram encontros virtuais para o compartilhamento de informações e esclarecimento de dúvidas.

Em tempo, a plataforma "Google Meet" tornou-se uma ferramenta importante para a integração e os bate-papos virtuais. Essa ferramenta esteve disponível a todos os alunos por meio do e-mail institucional. Em um dos encontros virtuais com os "calouros", os orientadores desenvolveram a dinâmica "Quem quer ser um engenheiro?", um jogo de perguntas e respostas referentes ao curso e às áreas de atuação de um engenheiro de minas. A atividade foi criada pelos próprios orientadores. Também por meio do "Google 
Meet', foi realizado um bate-papo com o professor José Fernando. O objetivo era incentivar e apresentar a importância da criação de um planejamento de carreira, o que deveria incluir a vida acadêmica dos alunos. A partir dessa atividade, os orientandos puderam se organizar e vislumbrar todas as oportunidades de ensino e extensão oferecidas pela universidade.

Além de possibilitar esses encontros, a plataforma em questão foi utilizada para a promoção de palestras ministradas por ex-alunos da universidade e convidados. Ao longo do ano de 2020, o projeto realizou quatro palestras com os respectivos temas e palestrantes: "Desafios e conquistas na trajetória profissional e apresentação do projeto Aripuanã - MT", com o engenheiro Tiago Alvarenga Vitorino da Silva; "Fogos em ambientes úmidos e subaquáticos", com o engenheiro e médico Carlos Reyes Ramos; "Tecnologia Mineral", com a engenheira Marina Lopes; "Planejamento integrado do minério de ferro: da mina à China", com o engenheiro Diogo Prata Bussular.

Ao fim de 2020, o projeto encerrou o período de acompanhamento dos alunos ingressantes no semestre 2020.1. De forma a buscar a otimização contínua do projeto e o melhor atendimento aos ingressantes do curso no semestre seguinte, foi criado um formulário de avaliação que foi devidamente preenchido pelos orientandos.

\section{RESULTADOS E DISCUSSÃO}

A implementação de novas atividades e a adesão dos alunos orientados são prérequisitos indispensáveis para a efetividade do projeto de Orientação Acadêmica. A partir dessa constatação, são elaborados questionários individuais de forma a obter informações e conhecer as expectativas dos alunos. Por meio de tais formulários, é possível acessar as principais demandas dos alunos atendidos e implementar adaptações necessárias ao projeto.

\subsection{Questionário para desenvolvimento de atividades}

Para o início das atividades do projeto, foi encaminhado um questionário aos discentes a fim de se coletar informações referentes ao comportamento e às rotinas durante a pandemia. Outra informação requerida foi propriamente o tipo de conteúdo que os orientandos desejariam que fossem levados a eles, de forma a proporcionar uma experiência personalizada, sem, obviamente, abrir mão das atividades previamente planejadas pela OAEM. O formulário continha 15 perguntas. Foram obtidas 20 respostas. Os resultados foram significativos e importantes para direcionamento do projeto. Dentre as perguntas feitas e respostas obtidas, as que mais se destacaram, por fornecer informações muito relevantes para o projeto, foram:

a) De 1 a 10, avalie o nível de ansiedade durante a quarentena, sendo um para leve e dez para ansiedade elevada.

De acordo com o gráfico apresentado (Figura 1), 70\% dos discentes apresentam ansiedade superior ao nível 5. 
Figura 1: Autoavaliação do nível de ansiedade.

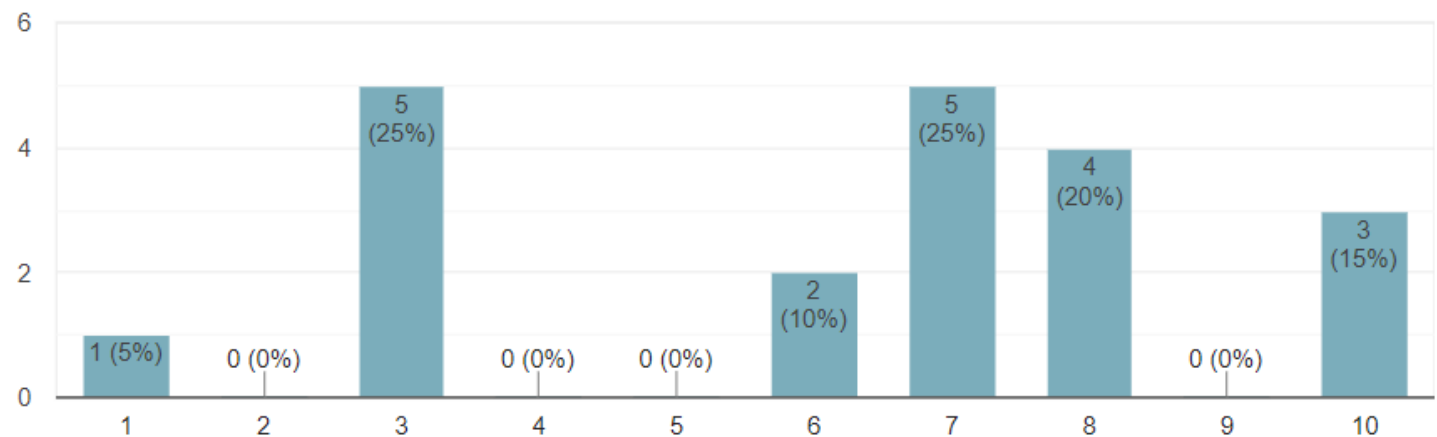

Fonte: Projeto Orientação Acadêmica, Google Forms, 2020.

A ansiedade é um sentimento comum entre os alunos do primeiro período. Muito das vezes devido a responsabilidade de se iniciar um curso superior e dar o primeiro passo mais direcionado a um futuro profissional. Via de regra, os alunos entram no curso ansiosos por informações a respeito das áreas de atuação e a situação do mercado de trabalho. Outro fator de grande relevância e que causa bastante ansiedade é, naturalmente, as diversas questões que implicam o ingresso em uma nova instituição de ensino e, eventualmente - para os alunos não naturais de Ouro Preto -, a mudança para uma nova cidade. Questionamentos e dificuldades iniciais com conteúdos de disciplinas ao qual os alunos não tiveram contato prévio, a necessidade de criar vínculos sociais e de se inserir na cidade, a adaptação em uma república ou casa partilhada, a necessidade de se afastar da família e do contexto em que estavam inseridos antes do início do curso são alguns dos desafios que se colocam diante da grande maioria e que ocasionam a geração de preocupações e consequentemente ansiedade.

b) Quais emoções tem predominado no seu dia?

Conforme o gráfico abaixo (Figura 2), as emoções predominantes nos discentes foram: ansiedade, afeto e alegria.

Figura 2: Emoções predominantes nos discentes em 2020.

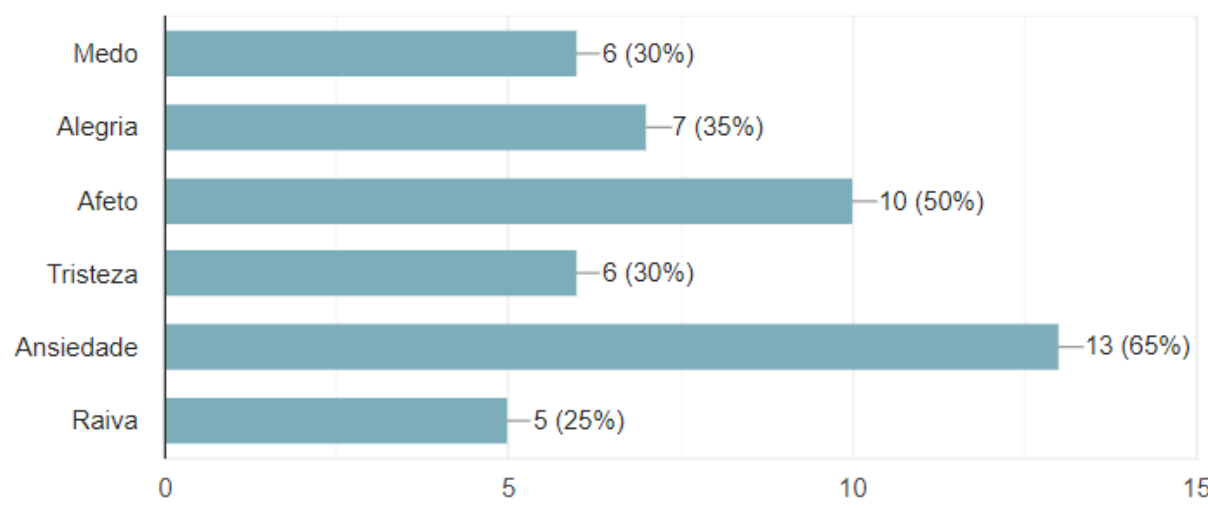

Fonte: Projeto Orientação Acadêmica, Google Forms, 2020. 
c) A situação pela qual passamos (de pandemia) causou algum impacto em relação à sua escolha pelo curso? Se sim, qual?

Das vinte respostas, foram obtidas três respostas "Sim", com justificativas que levavam em conta: a insegurança quanto ao mercado de trabalho, a preferência por outro curso, a proximidade geográfica do respondente com outra universidade e problemas de saúde.

d) Na sua opinião, qual o papel (o que você espera) da OAEM neste período de pandemia?

Foram obtidas respostas que envolviam disponibilidade para sanar dúvidas referentes ao curso e à universidade, orientações sobre atividades, cursos, conteúdos específicos que possam ser feitos remotamente, informações históricas e curiosidades sobre a cidade de Ouro Preto, mineração e áreas de atuação do engenheiro de minas.

As respostas obtidas demonstraram elevado nível de ansiedade entre os discentes iniciantes do curso frente à pandemia da Covid-19. De posse dessas informações, o projeto buscou orientação psicopedagógica com a psicóloga Franciele Lima, que, em um vídeo, tratou do assunto "Saúde mental em tempos de pandemia". O conteúdo foi postado nas redes sociais e encontrou-se disponível aos discentes que acompanharam as páginas oficiais do projeto nas plataformas Instagram e Facebook. O vídeo também foi disponibilizado no grupo de WhatsApp.

\subsection{Conteúdo nas redes sociais}

A partir das respostas recebidas na pergunta quatro, foi constatada a importância da geração de conteúdos relevantes e específicos relacionados ao curso. Por conseguinte, o projeto passou a desenvolver conteúdos que pudessem suprir tais demandas. Foram produzidos vídeos com profissionais e docentes do curso, por meio dos quais os alunos passaram a ter acesso a informações a respeito das áreas de atuação do engenheiro de minas, bem como as disciplinas lecionadas no curso, orientações e instruções a respeito da otimização do tempo.

Através do levantamento de dados fornecidos pela rede social "Instagram" foi constatado um elevado engajamento e interação com o conteúdo ali postado. A partir disso, os orientadores criaram conteúdos diversificados sobre variadas temáticas em formato de quizzes e templates, o que aumentou o tráfego e o engajamento social. A página da OAEM no Instagram conseguiu 100 novos seguidores no ano de 2020. Foram realizados mais 60 compartilhamentos das publicações e a interação em respostas em um dos quizzes chegou ao alcance de participação de 186 pessoas em 24 horas.

\subsection{Encontros síncronos e palestras}

Além das publicações nas redes sociais, foram promovidos encontros virtuais com os orientandos por meio da plataforma "Google Meet". Esses encontros tiveram como finalidade proporcionar a interação entre os alunos da turma, o repasse de informações como: bolsas e auxílios oferecidos pela universidade, apresentação das outras entidades estudantis, apresentação dos cursos e oportunidades ofertados pela Fundação Gorceix, atualização do calendário acadêmico, apresentação da plataforma utilizada pela a universidade (Minha UFOP). 
Foi realizada, ainda, uma dinâmica interativa que consistiu em um jogo de perguntas e respostas relacionadas às atribuições do engenheiro de minas e conteúdo das disciplinas iniciais do curso. O retorno obtido foi positivo, uma vez que os alunos não seriam contemplados com as informações repassadas fora da rotina de aulas presenciais da universidade, ainda que tais informações sejam muito importantes para que os alunos iniciantes permaneçam na graduação e obtenham um melhor aproveitamento das oportunidades no ambiente universitário.

Para um dos encontros remotos, foi convidado o professor José Fernando Miranda. Ele ressaltou a importância do planejamento de carreira. Após a palestra, foi solicitada aos participantes a elaboração de um planejamento para os cinco anos seguintes, considerando que o primeiro semestre aconteceu parcialmente em razão da paralisação.

Outras palestras ocorreram abertas ao público em geral e discentes de outras instituições de ensino. As palestras de Tiago Alvarenga (Figura 3), Carlos Reyes, Marina Lopes e Diogo Prata contaram com a presença de 40, 44, 24 e 32 pessoas, respectivamente. A iniciativa obteve êxito não apenas por levar informação aos alunos acompanhados pelo projeto, mas também por ter alcançado novos públicos, universidades e empresas.

Figura 3: Convite da primeira palestra, com Tiago Alvarenga.

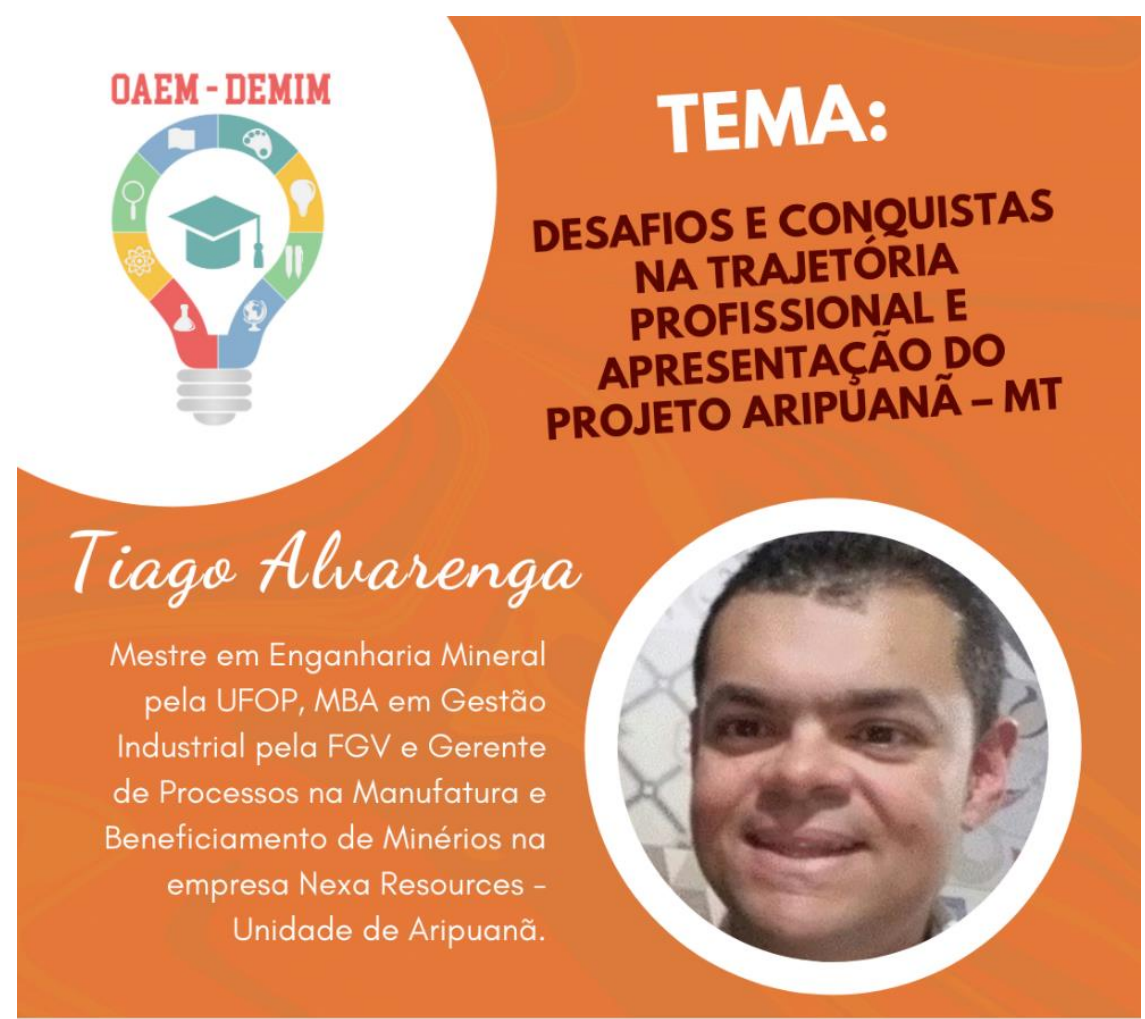

17 de junho, às 19h, no Google Meet Link a ser disponibilizado no dia da palestra

Fonte: Projeto de Orientação Acadêmica, Acervo pessoal, 2020.

\subsection{Formulário de avaliação final do projeto}

Obter o feedback dos orientandos do projeto é uma regra a cada fim de semestre letivo. Esta foi a forma mais apropriada para se mensurar o impacto do trabalho junto aos 
alunos e avaliar as metodologias, ferramentas e atividades desenvolvidas. O formulário de avaliação final do projeto contém 11 perguntas. Foram obtidas 7 respostas dos discentes. As perguntas e respostas que mais se destacaram respectivamente:

a) Quanto você aprendeu sobre a UFOP por meio da participação na OAEM (Figura 4)?

Figura 4: Avaliação de aprendizagem em relação às informações do projeto.

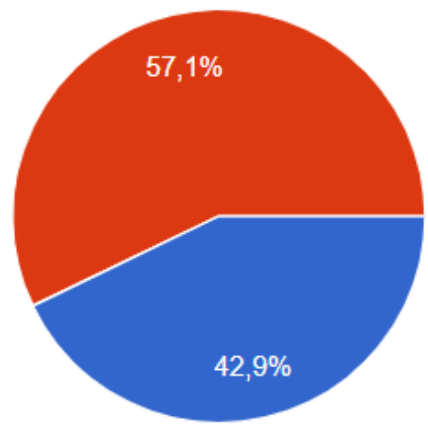

Fonte: Projeto Orientação Acadêmica, Google Forms, 2020.

b) O que é a OAEM para você agora? O projeto supriu suas expectativas?

\begin{abstract}
"Um programa que visa o auxilio aos estudantes iniciais do curso de engenharia de minas".

"Assim como todo mundo a OAEM precisou se adaptar ao sistema a distância e fez isso bem. Foram ofertadas palestras, a divulgação no instagram foi bem feita e alguns encontros online foram importantes para nos conectar com a faculdade. Creio que o aproveitamento seria bem maior caso estivéssemos presencialmente, mas para a situação atual a OAEM se adaptou bem ao nos orientar".

"A OAEM foi uma atividade que nos proporcionou um maior contato com o curso, com outros alunos de outros períodos, com conhecimentos sobre a mineração e grande troca de experiência. Infelizmente, por termos tido essa experiência de forma remota algumas expectativas acabaram sendo frustadas, como a participação de atividades práticas. No entanto, a atenção dos orientadores superou qualquer falta que senti".

"É uma forma de manter contato com a vida universitária. Sim, foi de acordo com o que esperava"

"Gostei da programação de orientação. Foi melhor do que esperava".

"O programa foi tudo que eu esperava, os participantes foram muito dedicados".
\end{abstract}

c) O que você sugere para a melhoria da OAEM? (Dicas e sugestões).

Dentre as respostas obtidas, havia: a oferta de mais encontros remotos entre os orientadores e orientandos. Tal sugestão foi considerada para o ciclo posterior, com alunos do semestre 2020.2. A expectativa é que sejam realizados encontros semanais com os orientandos, em dia e hora mais adequados para a maioria. 


\subsection{Evasão do curso de engenharia de minas em 2020}

Com base na planilha que discrimina dados relativos à evasão em todos os cursos, disponibilizada pela Universidade Federal de Ouro Preto (UFOP) na plataforma do Minha UFOP, é possível verificar a relevância do projeto de Orientação Acadêmica ao estabelecer comparativo entre o índice de evasão verificado entre alunos matriculados no primeiro período do curso de Engenharia de Minas e de outros cursos de graduação da instituição em um ano de pandemia.

No ano de 2020, o curso de Engenharia de Minas da UFOP teve um total de 16 alunos evadidos, sendo que 5 ocorreram por motivo de desligamento e o restante por cancelamento do curso. Dentre os 16 alunos, 4 estavam entre os matriculados no semestre 2020.1, ou seja, estiveram entre os orientandos do projeto ao longo de 2020. Os motivos apresentados pelos alunos evadidos foram: aprovação em outra instituição de ensino e aprovação em outro curso da UFOP. Um motivo não foi especificado e uma matrícula foi indeferida.

Analisando os dados do ano de 2019, no primeiro semestre, ocorreram 12 evasões do curso sendo 7 delas, mais que a metade, correspondente a alunos ingressantes no mesmo semestre. No segundo semestre, ocorreram 14 evasões, sendo 4 delas referentes a alunos ingressantes.

É possível constatar que a taxa de evasão do curso de Engenharia de Minas da UFOP não sofreu alteração devido à pandemia da Covid-19 e a consequente implementação do estudo remoto. Foi verificada uma taxa de evasão superior se comparada às taxas aferidas nos dois semestres anteriores, porém não houve variação significativa. Em tempo, a análise da taxa de evasão referente aos alunos do primeiro período do curso revela decrescimento na ordem 2019.1, 2019.2 e 2020.1

Em síntese, os dados referentes aos semestres 2019.2 e 2020.1 evidenciam uma queda na taxa de evasão na comparação com o semestre 2019.1. Estabelecendo correlação entre a queda no número de alunos evadidos ao trabalho desenvolvido pela Orientação Acadêmica, podemos constatar que o projeto vem cumprindo o seu propósito e que a adaptação das atividades teve resultados expressivos.

A ideia de fundamento e o objetivo principal do projeto foram disseminados, despertando outras universidades, bem como outros departamentos quanto a implementação de um projeto de orientação acadêmica para os discentes ingressantes nos cursos.

\section{CONSIDERAÇÕES FINAIS}

O isolamento social e o cancelamento das aulas presenciais em razão da declaração de pandemia da Covid-19 por parte da Organização Mundial da Saúde (OMS), em março de 2020, causaram grandes e significativas mudanças no âmbito das instituições de ensino e na lógica de ensino-aprendizagem. Ao longo do ano de 2020, o mundo teve de se readaptar e encontrar alternativas e soluções frente aos inúmeros desafios impostos pela pandemia. No segundo semestre de 2020, a Universidade Federal de Ouro Preto implementou o sistema do Período Letivo Especial (PLE) como forma de propor uma nova metodologia de ensino à distância - metodologia esta que seria indispensável nos semestres seguintes, com o avançar da pandemia e a consequente impossibilidade do retorno às atividades presenciais - e de verificar a acessibilidade digital de seus alunos.

A Orientação Acadêmica da Engenharia de Minas, por sua vez, também teve de se reinventar, ajustando atividades e propondo um novo formato de projeto, assegurando, assim, que o mesmo acontecesse no ambiente online. Até o mês de junho de 2020, o 
projeto se ateve a acompanhar os novos alunos através do grupo do "WhatsApp", no qual era dado apoio emocional a todos e eram constantes os envios de dicas sobre prevenção ao Coronavírus e informações pertinentes à universidade. Por meio das respostas obtidas nos formulários, foi identificada a necessidade de se ampliar a divulgação de informações, também, sobre cursos de capacitação bem como trazer palestras com profissionais do setor da mineração e da universidade.

Ao longo da incursão do projeto no ambiente online, pôde-se perceber que o conteúdo produzido para os novos alunos, poderiam serem úteis também aos alunos de períodos mais avançados, assim o projeto se fez ainda mais presente por meio das redes sociais, sobretudo no Instagram. O conteúdo postado gerou engajamento, atestado na maior procura pelo projeto e suas informações. Em média, 238 contas foram alcançadas com as publicações no feed do Instagram. Um dos quizzes obteve 186 respostas, sendo o conteúdo de maior interação com os seguidores do projeto na rede social.

As palestras abertas, além de terem contado com a presença do público alvo da Orientação Acadêmica, alcançou alunos veteranos, discentes de outras universidades, exalunos e, eventualmente, profissionais das empresas às quais os palestrantes eram vinculados. O feedback sobre as palestras foi significativo. A OAEM foi reconhecida por aproximar os profissionais de diversas áreas da mineração aos alunos e apresentar temas pertinentes ao universo da Engenharia de Minas de forma interativa e leve. Foram realizadas quatro palestras abertas com participação de, em média, 35 pessoas.

Há que se destacar o principal objetivo do projeto: a redução da taxa de evasão no curso de Engenharia de Minas. Com base em dados fornecidos pela universidade, podese afirmar que desde a criação do projeto, em 2013, o número de discentes ingressantes evadidos vem reduzindo. No ano de 2019, houve 11 desistências, já no ano de 2020, ocorreram 4 evasões envolvendo alunos do primeiro período do curso.

O desempenho da OAEM durante o período atípico de pandemia foi notório, tendo o projeto despertado a atenção dentro da instituição e também fora dela, devido o seu caráter pedagógico, instrutivo e de assistência aos alunos que, de repente, se veem inseridos em um novo contexto educacional, diante do desafio de criarem novos vínculos, terem o contato inicial com conteúdos novos e, eventualmente, terem que lidar com o imponderável da vida, a exemplo de um contexto pandêmico. Além de ser fator de destaque para a redução da taxa de evasão do curso, os resultados alcançados e a constante proeminência da OAEM como entidade consolidada no Departamento de Engenharia de Minas da UFOP são tidos como conquistas para os orientadores do projeto.

\section{Agradecimentos}

Agradecemos ao apoio da Universidade Federal de Ouro Preto, aos alunos ingressantes em Engenharia de Minas no primeiro semestre de 2020 que participaram do projeto. 


\section{REFERÊNCIAS}

CAPOVILLA, S. L., \& SANTOS, A. A. A. Avaliação da influência de atividades extramuros no desenvolvimento pessoal de universitários. 2001. Psico-USF, 6, 4958.

FONSECA, A. M. V., SANTOS, E. A. R., ALVES, V. K. HENRIQUES, A. B., PEREIRA, C. A Papel da orientação acadêmica no acolhimento aos calouros da engenharia de minas. Cobenge, 2019.

GARBIN, Tânia Rossi. GESTÃO EAD: a evasão e a permanência dos alunos em curso a distância. Disponível em:

http://professor.ufop.br/sites/default/files/trgarbin/files/esud2012 gestao da ead.pdf.

Acesso em: 19 mar.2021.

HERMES, Felipe. De sem teto ao PhD na Califórnia, como Gil desafia a estatística de mobilidade social no Brasil. Disponível em: https://www-infomoney-com-

br.cdn.ampproject.org/c/s/www.infomoney.com.br/colunistas/felippe-hermes/de-sem-tetoao-phd-na-california-como-gil-bbb-desafia-a-estatistica-de-mobilidade-social-nobrasil/amp/. Acesso em: 14 abr 2021.

Orientação Acadêmica. Ouro Preto, 2020. Instagram: oaemdeminufop. Disponível em: https://instagram.com/oaemdeminufop?igshid=68x5fj39a0dk . Acesso em: 02 mar. 2020.

ROBBINS, S., LAUVER, K., Le, H., DAVIS, D., LANGLEY, R., \& CARLSTRON, A. (2004). Do psychological and study skill factors predict college outcomes? A metaanalysis. Psychological Bulletin, 130(2), 261-288.

SANTOS, J . R., ZABOROSKI, E. A. Ensino remoto e pandemia covid-19: desafios e oportunidades de alunos e professores. 2020. Revista Interações. Colégio Militar de Santa Maria (CMSM).

SOARES, A. P., ALMEIDA, L. A., DINIZ, A. M., \& GUISANDE, M. A. Modelo multidimensional de ajustamento de jovens ao contexto universitário (MMAU): Estudo com estudantes de ciências e tecnologias versus ciências sociais e humanas. 2006. Análise Psicológica, 1(XXIV), 15-27.

ORIENTAÇÃO ACADÊMICA. Formulários eletrônicos. 2020. 2p. Universidade Federal de Ouro Preto. Orientação Acadêmica 2020.1. Disponível em:

https://docs.google.com/forms/d/1 xtnibIBP2cxX5eYCTeGXxjriVXECkl5SahEWJHazFWg/e dit . Acesso: 13 mar.2021.

ORIENTAÇÃO ACADÊMICA. Formulários eletrônicos. 2020. 1p. Universidade Federal de Ouro Preto. Questionário Final de Avaliação do Projeto. Disponível em:

https://docs.google.com/forms/d/12Hp8YSsNgJOmSJL5UMZdeM7omWgKWcbalir3sRtco7 U/edit . Acesso: 27 mar. 2021. 


\title{
ACADEMIC ORIENTATION AND THE COVID-19 PANDEMIC
}

\begin{abstract}
This article presents the adaptations made by the Academic Orientation of the Mining Engineering Course at the Federal University of Ouro Preto - Minas Gerais (OAEM UFOP-MG), throughout the year 2020, to guarantee the development of the project during the COVID-19 pandemic. With the mission of enabling the insertion of students in the academic environment in the city of Ouro Preto and, mainly, reducing the dropout rate, the project took place remotely, exploring the various possibilities offered by the internet. Video content, online lectures about the course and other subjects related to the area of Mining Engineering, quizzes and group dynamics were among the activities developed with 30 new undergraduates of the course. Some of the results achieved were the positive feedback given by the students and the realization of departments within UFOP and other institutions of the relevance of a support group aimed at new students. Despite the lack of viability of face-to-face meetings, in compliance with the measures of social isolation recommended by the World Health Organization (WHO), the project expanded its performance and contributed to the students' staying in the course. Data released by UFOP indicate that the course's dropout rate has fallen in 2020 when compared to 2019, a year of regular face-toface activities. Therefore, it's possible to verify the relevance of the project for the strengthening of what is a university's biggest mission: to train professionals and citizens.
\end{abstract}

Keywords: Academic Orientation. Mining engineering. Adaptation. Covid-19. Teaching project. 